\title{
Risk Factors and Symptomatic Diseases in Managed Honeybee Colonies: A Case Study from Seka Chekorsa District of Jimma Zone, Oromia, Ethiopia
}

\author{
Desta Abi Gemedi* \\ Oromia Agricultural Research Institute (IQQO), Addis Ababa, Ethiopia
}

*Corresponding Author: Desta Abi Gemedi, Oromia Agricultural Research Institute (IQQO), Addis Ababa, Ethiopia

\begin{abstract}
Field based study was conducted in Seka Chokersa district, Ethiopia with overall objective of assessing symptomatic disease condition of honeybee pests, parasites and pathogens; associated risk factors; and appraising their potential effects on beekeeping. A total of 36 stationary apiaries having well established 722 honeybee colonies were randomly sampled for inspecting of honeybee pests and pathogens. Adult worker bees, bee brood and hive debris were sampled from the sample honeybee colonies under two different time conditions. Samples were clinically tested both in the field and under laboratory for presence of economically important honeybee pests and pathogens. Comparatively, Aethina tumida, Achrolla grisella and Varroa Destructor were clinically identified the most abundant honeybee pests. Even though it is not in significant degree, there has been a positive indication for some not previously reported to present honeybee bacterial disease causing pathogen. Apparent reduction in hive products was observed in the pest affected honeybee colonies. It is suggested that detailed and large scale study be conducted to declare the actual absence of those honeybee pests, parasites and pathogens (which were not tested positive. It is remarkable that the current research has documented present status for major honeybee pests and pathogens in the study area and, therefore can help all stake-holders in designing any of their research and development endeavors with regard to the subsector.
\end{abstract}

Keywords: Symptomatic diseases, Risk factors, managed honeybees, Seka Chekorsa

\section{INTRODUCTION}

It has been widely reported that honey is threatened by an array of interacting factors (eg: vander Zee R, Pisa et al. 2012; Lee KV, et al.,2015). losses of managed honey bee colonies have been reported from various countries (eg: Seitz N, Traynor KS, et al,2014-2015, LeeKV, etal,2013-2014). In a list of serious causes for unhealthy conditions in managed honeybee colonies are different pests and pathogens. Honeybee colony loss problem can be addressed by identifying status of possible disease conditions and associated risk factors. This activity can help describe the status-quo of bee health and show trends in loss rates, if frequently undertaken. And on the basis of this strategy for improvements of bee health will always become implicit through identification of important factors to be examined under a modeling works. As disease occurrence and colony losses vary widely between different countries and climatic regions (eg: van der Zee R, Pisa et al. 2012; Lee KV, et al.,2015), a complete picture of the distribution of bee diseases is necessary to understand problems on national but also on international level.

Studies showed that plethora of honeybee pathogens and pests of temperate origin have been on a pace of spreading out to the tropical climates (Elliud Muliet et al, 2014). Most of the pests, parasites and pathogens affecting global honeybee colony health are distributed throughout Africa (Hussein, 2000 and Elliud \& Harland, 2014).

Ethiopia, with over 10 million honeybee colonies has been considered the heart of honey and bees wax production in Africa (Tessega Belie, 2009). Due to its diverse ecological and climatic conditions, the country is home to some of the most copious flora and fauna in the continent (Desalegn Begna Rundassa, 2001). Its forests and woodlands contain plant species that provide surplus nectar and pollen to foraging bees (Gidey Yirga and Mekonen Teferi, (2010). The country is estimated to produce 53,000 
Risk Factors and Symptomatic Diseases in Managed Honeybee Colonies: A Case Study from Seka Chekorsa District of Jimma Zone, Oromia, Ethiopia

tons of honey per annum (CSA, 2014), thus shares $23.5 \%$ of Africa's and $2.35 \%$ of world's honey production. This makes the country rank 1st in the continent and 10th in the world (Abebe Alemu et al, 2011).

Despite the tremendous beekeeping resources, in Ethiopia, honey and bees wax production has so far been much more below its annual estimate (Gidey Yirga \& Bethelhem Koru, 2016). The general image shows that in many beekeeping places, production of honey is unusually shrinking. Benefit from beekeeping sector to the nation and beekeepers has generally been not satisfactory (Tolera Kumsa and Dejene Takele, 2014). Several factors were suggested to have been constraining honeybees and therefore deteriorating beekeeping activity in the country (Yirga Gidey \& Teferi Mekonnen, 2010). Like in other beekeeping regions, in Ethiopia, honeybees may be affected by myriad of pests and pathogens (Dabessa Jatema \& Belay Abebe, 2015). However, comprehensive information on honeybee health and evidence of diagnosing presence, prevalence and predictable consequences of honeybee pests, parasites and pathogens together with the major risk factors has been little so far.

Therefore, the aim of the present study was to symptomatically appraise honeybee health conditions and the impact associated with beekeeping practices and honeybee performance. Thus, the prevalence of infection and disease of pathogens and parasites in seka chekorsa was determined by undertaking clinical and laboratory studies. Furthermore, factors related to beekeeper characteristics, colony status and health were analyzed in correlation with influences to honeybee colony performance.

\section{Materials ANd Methods}

\subsection{Apiary Selection}

For the purpose of this study, different data were collected from apiaries and honeybee colonies. Secondary data related to beekeepers, honey production and honeybee colonies were collected from Livestock and Fishery Resources Agency (LFRDA) office, Seka Chokersa district via desk discussion with office experts and reviewing of official records.

Field based apiaries observation or microscopic inspection were undertaken to diagnose symptomatic presence of honeybee disease conditions and risk factors. The sample beekeeping apiaries were selected based on accessibility to the main road and willingness of the beekeepers in providing sample honeybee colonies. Accordingly, a total of 36 well established apiaries were purposively sampled from a sample of 15 operational apiaries comprising of 600 established honeybee colonies for diagnostic study of honeybee pests, parasites and pathogens. However, the sample size for apiaries and honeybee colonies could not be estimated in advance of the study and was therefore, subjectively determined based on the likelihood for presence of relevant sampling material for field diagnosis and laboratory studies.

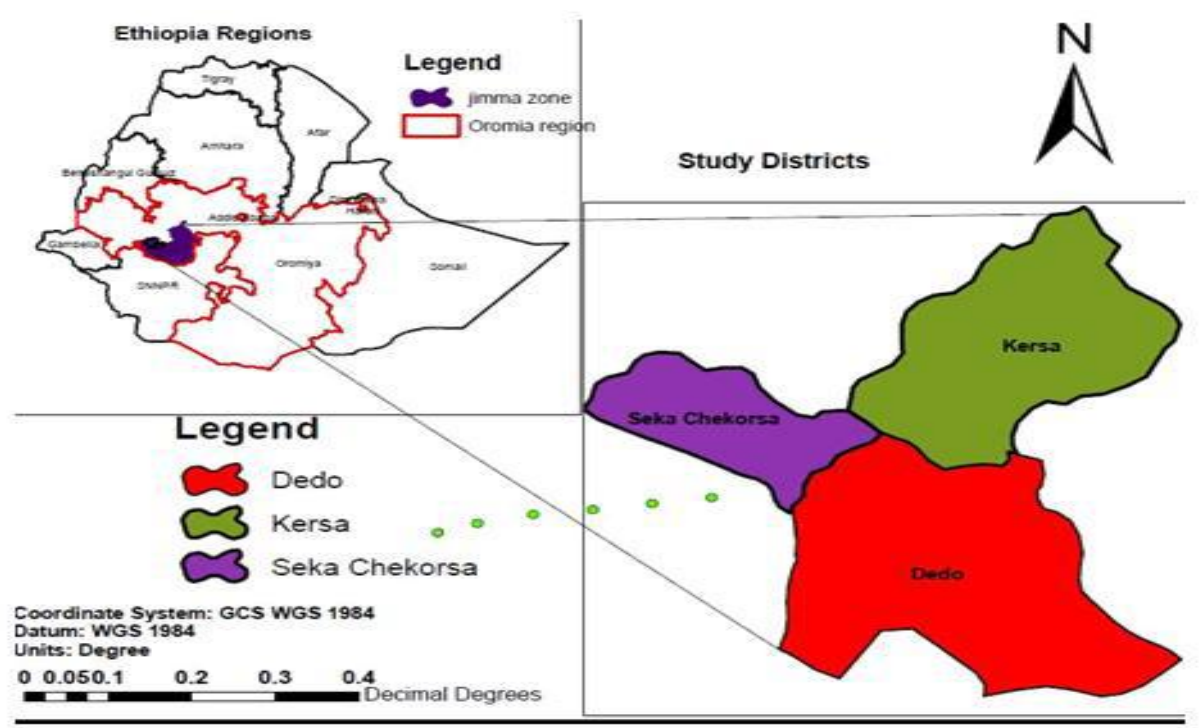

Figure1. Map of location of the Seka Chekorsa District in Jimma zone

\subsection{Data Collection Methods}

From the study district, three data enumerators with relevant expert and experience were chosen and oriented about the type of data to be collected prior to the commencement of data collection. In this 
activity, different biological identifications and relevant symptoms of respective honeybee pest, parasite and pathogen diagnosis were reviewed and included in the

In the selected apiaries, to use sampled honeybee colonies which had been placed in transitional and frame hives on no pay basis, the owners of the hives were convinced in advance of actual field study; their honeybee colonies with traditional hive were used on payment basis.

Seasonal hives inspection and sample bees and bee brood collection was made in each apiary for examination of occurrence for disease symptoms of pests, parasites and diseases in every selected apiary. Sampled apiaries and honeybee colonies were marked for ease of seasonal data collection. Beekeepers were convinced not to dislocate the selected hives for any purpose, at least, for the study period. In the selected apiaries, inspection of honeybee colonies and sampling of a live worker bees and bee brood (both live and decayed) was carried out. However, worker bees and bee brood were collected from the designated hives and used for subsequent laboratory tests. During this time, samples of pests and parasites which were found in or around hives (either alive or dead) were collected for laboratory confirmation.

To sample adult alive bee, without killing from field wooden box of $12 \mathrm{mmx} 15 \mathrm{mmx} 20 \mathrm{~mm}$ was constructed to collect worker bees while a $4 \mathrm{mmx} 10 \mathrm{~mm}$ postal bags for bee brood samples was used to collect brood samples. In this process, bees were made concentrated at the centre in hives where selected brood combs are located. Using bee brush, the bees were brushed off in a bucket, and then about 100 to 200 bees were scooped and put into a wooden box which were then covered with a piece of wooden cover and plastered. A $5 \mathrm{mmx} 5 \mathrm{~mm}$ brood area was cut and put in to the postal bags and sealed. During this study, number of frames of worker honeybee, bee brood, nectar, honey and pollen was also estimated using Lebefielder method as it was used by (Retschnig, 2015).

Samples were taken to Bee Protection Laboratory, Holeta Bee Research Center (HBRC), Ethiopia for microscopic examinations. Respective standard laboratory protocols which had got accreditation under International organization for Animal Health (OIE) were reviewed and tracked for detection and quantification of honeybee and honeybee pests, parasites and diseases. Major research data like existed honeybee pests, parasites and diseases, season of occurrence, number of honeybee colonies per apiary, number of sample apiaries and honeybee colony population.

Field and laboratory inspection was conducted during active and dry seasons of the study area. The visits were conducted by experienced bee inspector's/data collectors, who were specially trained. During each inspection, the bee inspectors filled in hive inspection data about the beekeeping operation, the visited apiary and about the disease conditions of each inspected colony. Colony inspections were conducted by estimating the colony size and examining the bees, the brood combs and the front of the colony for signs of pests and diseases. Bee inspectors either diagnosed a disease on-site or took samples of suspicious material for laboratory analysis. In apiaries with more than ten colonies, ten colonies were selected randomly for the surveillance study. If ten or less than ten colonies were present in the apiary, all colonies were sampled. Furthermore, the samples were searched visually for the bee pests: Small Hive Beetle, Varroa Mites and Wax Moths (OIE,2008; Chauzat M-P ,2013; Cornelissen B,2018). Samples with suspicion for AFB or EFB (brood sample), Bee Beetles (samples of the suspicious beetle, larvae or eggs) or Varroa mites (samples of suspicious mites) had to be sent to HBRC for confirmation or further investigation, as these are notifiable diseases. Please note that for calculating the prevalence of pests and pathogens, we took only into account the clinical sign data.

\subsection{Data Analysis}

The collected data were cleared \& stored into Microsoft Excel program for further analysis. SPSS version 16 statistical package was used to analyze the data. Summarized data was presented in the form of tables and figures. The questioner survey data, obtained in this study were analyzed using descriptive statistics described by (Musa et al., 2006).

\section{RESULTS AND DISCUSSION}

\subsection{Major Honeybee Risk Factors}

Risk factors for occurrence of unhealthy conditions in managed honeybee colonies were assessed (Figure1). It was found that artificial feeding (20\%), honeybee colony marketing (25\%), honeybee 
Risk Factors and Symptomatic Diseases in Managed Honeybee Colonies: A Case Study from Seka Chekorsa District of Jimma Zone, Oromia, Ethiopia

swarm catching (32\%), migratory beekeeping (5\%), drifting (29\%) and robbing (32\%) are the most prevailing risk factors in the study area. These mentioned honeybee management activities can have adverse effect if not used with due care and cause unhealthy conditions to honeybees. Therefore, in honeybee health, the quantity and ability to spread of the pathogen is also very important (Food and Agriculture Organization of the United Nations,2008).

From this finding it can be concluded that there will be augmented risk to be contracted for any disease condition in the managed honeybee colonies examined in this study. Therefore, beekeepers in the study area should be trained on improved beekeeping practices in order to help mitigate chance of honeybee diseases occurrence and harm beekeeping activities in the study area. Particularly, beekeepers need to have better awareness on dissemination of honeybee diseases through artificial feeding, honeybee colony marketing, honeybee swarm catching, robbing and drifting of honeybee colonies. However, migratory beekeeping and honeybee marketing had been viewed to be of a less risk of concern in the present study.

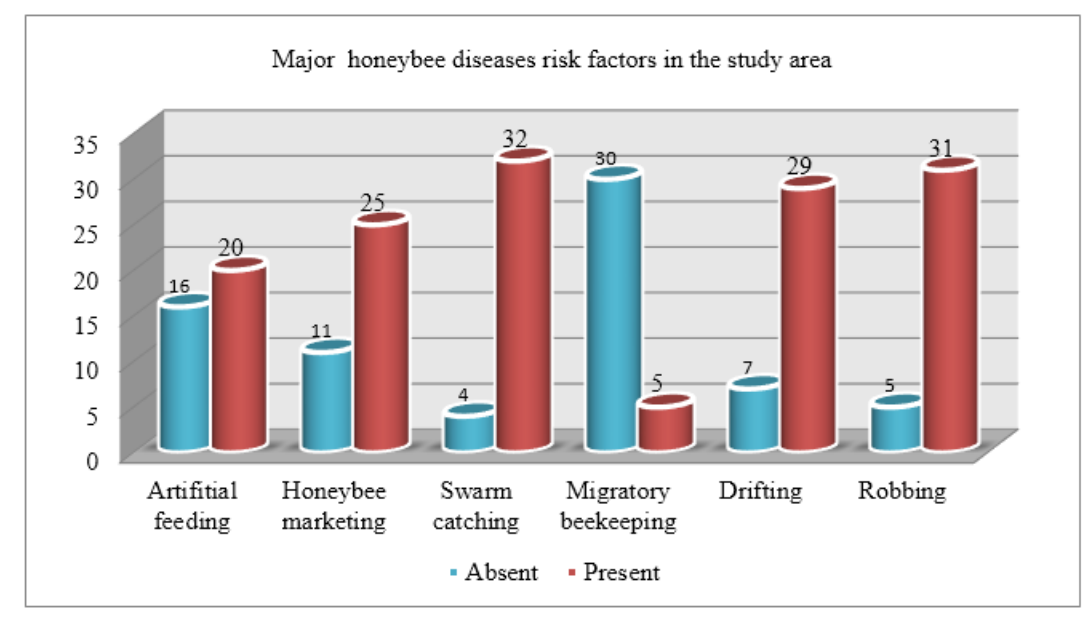

Figure2. Presence of some honeybee diseases risk factors in Seka Chekorsa district of Jimma zone,Oromia, Ethiopia

\subsection{Presence of Common Honeybee Pests and Pathogens: A Symptomatic Examination}

The present intense apiary inspection and field observation has shown that there are abundant honeybee pests and pathogens in the study area (Figure 2). There had been evident symptoms and clinical symptoms for presence of several honeybee pests (Wax moths, Bee Beetles, Bee Lices, Ants and Birs). However, in this study, it was recorded that there is no noticeable symptoms for honeybee disease causing microbes like Bacillus larvae (AFB), Bacillus pluton (EFB), Nosema apis, Melphigae mellificae, Aschosporera apis, Aspergillus flavus, Varroa spp and viral pathogens. For further, confirmation and clarification of the presence of these honeybee diseases causing pathogens wider study and welldesigned laboratory study is recommended. The current result is in agreement with Assefa, (2009); Kerealem et al., (2009); Tesega, (2009); Workneh and Paskur, (2011); Adeday et al., (2012); Assemu et al, 2013); Nebiyu and Mesele, 2013; Haftu et al., (2015); Haftu and Gezu, (2014) who reported that honeybee diseases are not the major problems of beekeeping in all regions of Ethiopia.

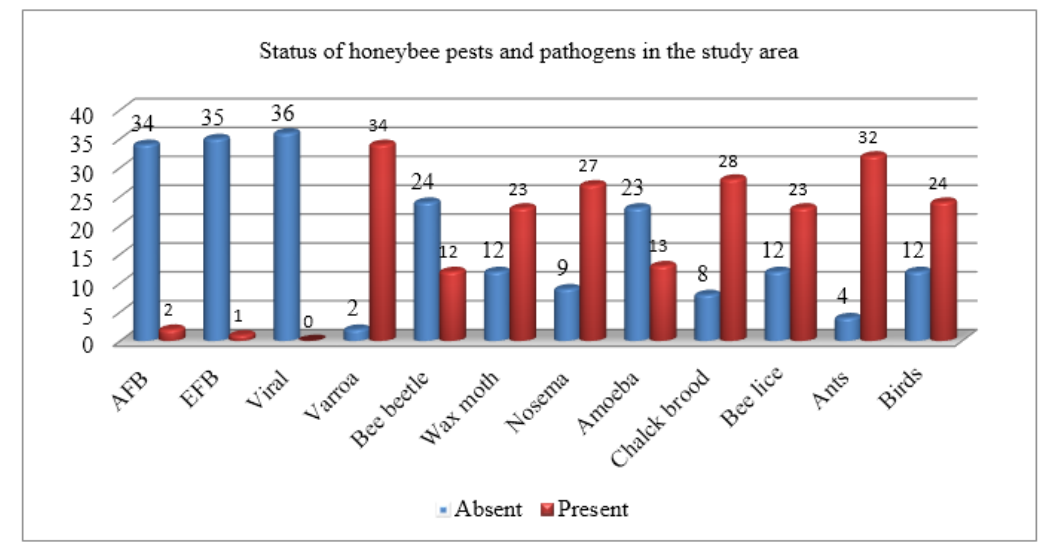

Figure3. Clinical presence of honeybee pests and pathogens in Seka Chekorsa district of Jimma Zone,oromia, Ethiopia 
Risk Factors and Symptomatic Diseases in Managed Honeybee Colonies: A Case Study from Seka Chekorsa District of Jimma Zone, Oromia, Ethiopia

\subsection{Colony Size and Honeybee Performance}

Apiary expansion and colony size is one of the sources for honeybee unhealthy condition to happen. This is to explain that increased number of honeybee colony can have indirect contribution for occurrence and distribution of honeybee disease causing pests and pathogens and impacting honeybee colony performance as well. In this study, status of different hive products (number of honey, nectar, pollen and brood) was assessed in hives suspected and not suspected for presence of honeybee pests and pathogens under conditions of apiaries of different size. Therefore, it was found that there has been evident decrease in apiaries suspected with honeybee diseases (figure 4a) as the number of honeybee colonies expanded as compared to apiaries that were not suspected with clinical diseases (figure 4b).
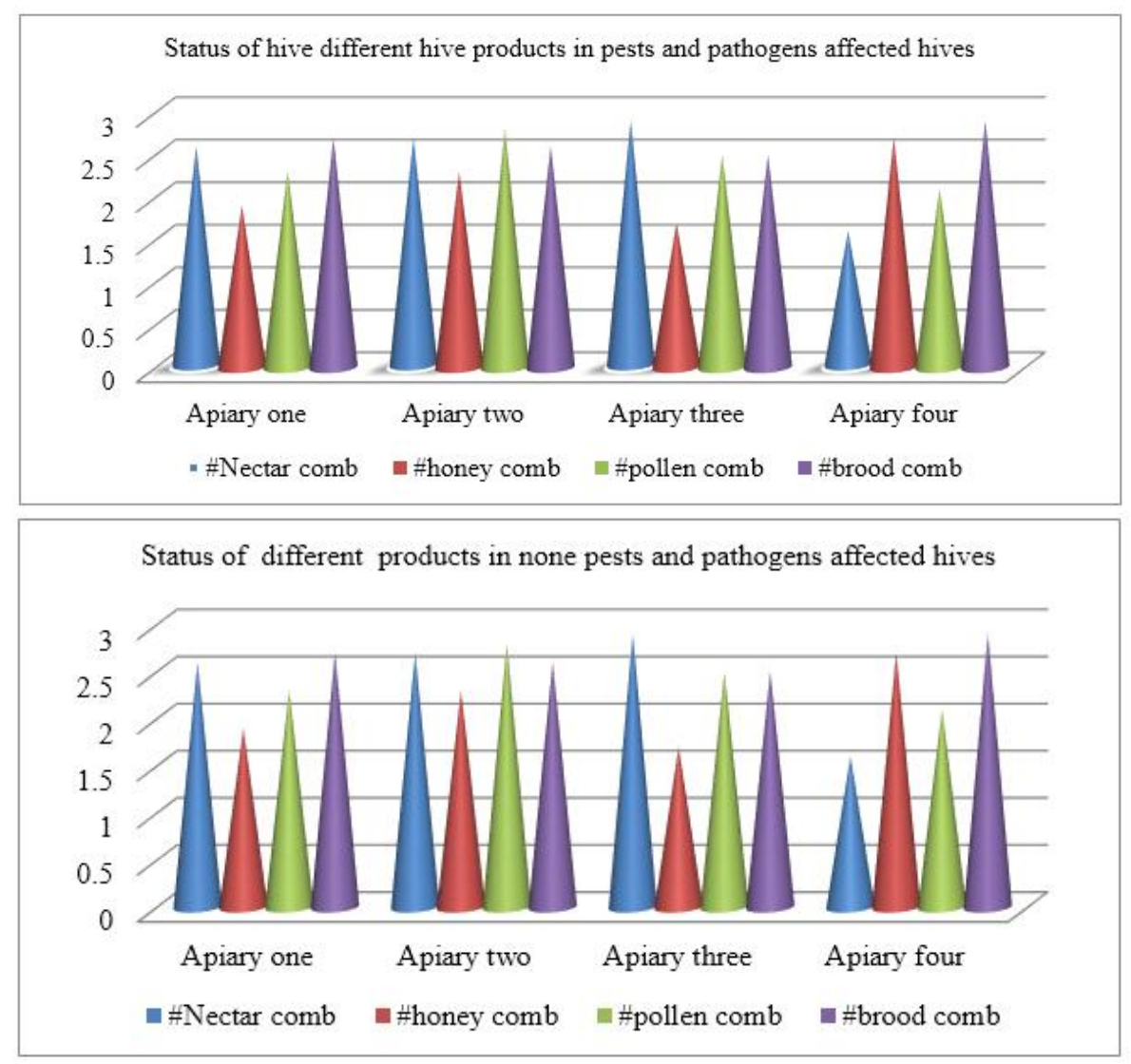

Figure4. Comparison of honeybee pests and pathogens influence on number of frame of common hive products (figure $4 a$ and $4 b$ ) of honeybee colonies in apiaries of different size

\section{CONCLUSION AND RECOMMENDATION}

Honeybees are susceptible to various diseases, some of which are very contagious and diffusive. It is very important that the beekeeper is able to recognize the first signs of disease or infestation in hives and knows how to proceed. This practice outlines the factors that play an important role in the outbreak of a disease and describes the classification of bee diseases.

From the present diagnostic field study, it can be concluded that the level of incidence of prevailing honey bee pests and pathogens are different. However, on comparison, Bee Beetles, Wax Moths and Varroa Mites were identified the most abundant honeybee pests. Although, it is in an insignificant degree, there has been a positive indication even for presence of some not previously reported to present honeybee diseases causing pathogens of different classes. Apparent reduction in different hive products was observed in the pest affected honeybee colonies. It is suggested that detailed and large scale study be conducted to declare the actual absence of those honeybee pests, parasites and pathogens to help complete these study to the best of its anticipated purpose. It is worth noting that the current research has documented present status for major honeybee pests and parasites in the study area and, therefore can give valuable information for all stake-holders to design research and develop strategies for intervention. For future beekeeping improvement local beekeepers has to be trained on how to sustainably protect their honeybee colonies not be affected by honeybee pests and pathogens. 
Risk Factors and Symptomatic Diseases in Managed Honeybee Colonies: A Case Study from Seka Chekorsa District of Jimma Zone, Oromia, Ethiopia

\section{REFERENCES}

[1] Abebe Alemu, Gemeda Abebe, Wonde wossen Tsegaye, Lemu Golassa (2011). Climatic Variables and Malaria Transmission Dynamics in Jimma Town, South West Ethiopia, Parasites \& Vectors, 4(1), 30-47.

[2] Chauzat M-P, Cauquil L, Roy L, Franco S, Hendrikx P, Ribière-Chabert M. Demographics of the Euro- pean Apicultural Industry. PLoS One. 2013; 8(11):e79018. https://doi.org/10.1371/journal.pone. 0079018 PMID: 24236084

[3] Cornelissen B, Neumann P. How to Catch a Small Beetle: Top Tips for Visually Screening Honey Bee Colonies for Small Hive Beetles. Bee World. 2018; 95:99-102.

[4] CSA (2014). Key Findings of 2013/2014 Agricultural Sample Survey.A Report, Central Statisticl Agency,Addis Ababa,Ethiopia.pp.24.

[5] Desalegn Begna Rundassa. (2001). Chalk brood in ethiopia. Bees for Development Journal 78, 78. 16-24.

[6] Desalegn Begna. (2015). Occurrences and Distributions of Honeybee ( Varroa mite) Apis mellifera Jemenetica ) ) in Tigray Region, Ethiopia. Journal of Fisheries \& Fisheries Livest Production, 3:1, 1-4.

[7] Elliud M., Harland Patch, M. F. (2014). Evaluation of the Distribution and Impacts of Parasites, Pathogens, and Pesticides on Honey Bee (Apis mellifera) Populations in East Africa. Retrieved from (http://www.nsf.gov/bio/bread/index.jsp on 16 of June,2016.

[8] Gidey Yirga and Mekonen Teferi (2010). Participatory Technology and Constraints Assessment to Improve the Livelihood of Beekeepers in Tigray Region, northern Ethiopia. MEJS, 2:1, 76-92.

[9] Hornitzky MAZ, Clark S. Culture of Bacillus larvae from bulk honey samples for the detection of Ameri- can foulbrood. J Apic Res. 1991; 30(1):13-6.

[10] Hussein M. H. (2000). Beekeeping in Africa:I. North, East, North-East and West African countries. Apiacta, $1: 3,2-48$.

[11] mit Columbia-Blut-Schrägagar. Berl Munch Tierarztl Wochenschr. 1985; 98:61-2. PMID: 3883984

[12] OIE. Chapter 2.2.6. Infestation of honey bees with Tropilaelaps spp. In: OIE. Manual of Diagnostic Tests and Vaccines for Terrestrial Animals. Paris: World Organisation for Animal Health; 2008.

[13] Plagemann O. Eine einfache Kulturmethode zur bakteriologischen Identifizierung von Bacillus larvae

[14] Retschnig, G. (2015). Methods in honey bee research.Agroscope,1 (July), 1-19.

[15] Tessega Belie. (2009). Honeybee Production and Marketing Systems, Constraints and Opportunities in Burie District of Amhara Region,Ethiopia. Bahir Dar University.pp.131.

[16] Tolera Kumsa and Dejene Takele. (2014). Assessment of the effect of seasonal honeybee management on honey production of Ethiopian honeybee ( Apis mellifera ) in modern beekeeping in Jimma Zone. Research Journal of Agriculture and Environmental Management, Research Journal of Agriculture and Environmental Management, 3:5, 246-254.

Citation: Desta Abi Gemedi," Risk Factors and Symptomatic Diseases in Managed Honeybee Colonies: A Case Study from Seka Chekorsa District of Jimma Zone, Oromia, Ethiopia” International Journal of Research Studies in Biosciences (IJRSB), 8(2), pp 21-26. DOI: http://dx.doi.org/10.20431/2349-0365.0802004

Copyright: (C) 2020 Authors. This is an open-access article distributed under the terms of the Creative Commons Attribution License, which permits unrestricted use, distribution, and reproduction in any medium, provided the original author and source are credited. 